\title{
Produção de fitomassa e acúmulo de nutrientes pela aveia-preta em função da aplicação de calcário e gesso em superfície na implantação do sistema plantio direto
}

\author{
Black oat phytomass and nutrient accumulation as affected by surface application of lime and \\ phosphogypsum during establishment of no-tillage system
}

\author{
Rogério Peres Soratto $^{\mathrm{I} *}$ Carlos Alexandre Costa Crusciol ${ }^{\mathrm{I}}$
}

\section{RESUMO}

Com o objetivo de avaliar a influência da aplicação de calcário e gesso em superfície, na implantação do sistema plantio direto, sobre a produção de matéria seca e ciclagem de nutrientes pela aveia-preta, foi realizado um experimento, nos anos de 2003 e 2004, em um Latossolo Vermelho distroférrico. O delineamento foi de blocos casualizados com parcelas subdivididas e quatro repetições. As parcelas foram constituídas por quatro doses de calcário dolomítico $\left(0,1.100,2.700\right.$ e $\left.4.300 \mathrm{~kg} \mathrm{ha}^{-1}\right)$ e as subparcelas pela aplicação ou não de $2.100 \mathrm{~kg} \mathrm{ha}^{-1}$ de gesso agrícola. Os tratamentos foram aplicados em outubro de 2002. A aplicação de calcário em superfície não afetou a produção de matéria seca da aveia-preta em sistema plantio direto, tanto na presença quanto na ausência de gesso. O teor de Ca e $\mathrm{S}_{-} \mathrm{SO}_{4}^{2-}$ no solo e a absorção de $S$ pela cultura da aveia-preta foram incrementados pela aplicação de gesso agrícola. Em ano com menor disponibilidade hídrica, a aplicação de gesso agrícola em superfície favoreceu a produção de matéria seca e aumentou os teores de $\mathrm{N}$ e Ca, e o acúmulo de $\mathrm{N}$, Ca, Fe e Zn pela aveiapreta.

Palavras-chave: Avena strigosa, acidez do solo, nutrição mineral, calagem, macronutriente, micronutriente.

\section{ABSTRACT}

In order to evaluate the influence of lime and phosphogypsum surface application, during establishment of no-tillage system, on black oat dry matter yield and nutrient cycling, an experiment was carried out during 2003 and 2004, on a Haplorthox. A randomized complete block design, in split-plot arrangement, and four replications was used. The plots consisted of four dolomitic limestone levels $(0 ; 1,100$; 2,700; and 4,300 $\left.\mathrm{kg} \mathrm{ha}^{-1}\right)$. The subplots were represented by presence or absence of phosphogypsum application $(2,100 \mathrm{~kg}$ $\left.h^{-1}\right)$. The treatments were applied in October 2002. Surface application of lime did not affect black oat dry matter yield in no-tillage system, in both presence and absence of phosphogypsum application. Phosphogypsum increased $\mathrm{Ca}$ and $\mathrm{S}_{-} \mathrm{SO}_{4}^{2-}$ contents in soil and $\mathrm{S}$ uptake by black oat crop. In year with less water availability, the surface application of phosphogypsum promoted increasing on dry matter yield, $N$ and $\mathrm{Ca}$ contents, and $\mathrm{N}, \mathrm{Ca}, \mathrm{Fe}$, and $\mathrm{Zn}$ accumulation by black oat crop.

Key words: Avena strigosa, soil acidity, mineral nutrition, liming, macronutrient, micronutrient.

\section{INTRODUÇÃO}

O sistema plantio direto (SPD) associado à rotação de culturas é uma das melhores alternativas para a conservação dos recursos naturais na utilização agrícola dos solos (CAIRES et al., 2005). Por isso, a área ocupada pelo SPD tem aumentado rapidamente no Brasil nos últimos anos. Na safra de 2003/2004 foram cultivados 21,8 milhões de hectares sob esse sistema (FEBRAPDP, 2006), correspondendo a cerca de 50\% da área cultivada com culturas graníferas. Observa-se, inclusive, aumento de interesse no estabelecimento de culturas no SPD em áreas anteriormente cultivadas no sistema convencional de preparo do solo ou sob pastagens, sem promover o revolvimento do solo para incorporação de corretivos. A aplicação de gesso agrícola em superfície é apontada como uma alternativa para a melhoria do ambiente radicular, nos primeiros anos de cultivo, época em que a ação do calcário, por ser pouco solúvel e apresentar baixa mobilidade no

IDepartamento de Produção Vegetal (Agricultura), Faculdade de Ciências Agronômicas (FCA), Universidade Estadual Paulista (UNESP), Campus de Botucatu, CP 237, 18610-307, Botucatu, SP, Brasil. E-mail: soratto@fca.unesp.br.*Autor para correspondência. 
solo, ainda não atingiu as camadas subsuperfíciais (CAIRES et al., 2003).

O aporte de elevada quantidade de resíduos ao solo, seja pelos restos de culturas produtoras de grãos ou de culturas implantadas com a finalidade específica de produção de palha (BORTOLINI et al., 2000), é um dos principais requisitos para sustentabilidade do SPD em condições tropicais e subtropicais (SANTI et al., 2003). Porém, em regiões com inverno seco, a produção e a manutenção de cobertura vegetal do solo para o SPD têm sido um dos principais desafios da pesquisa agronômica.

A aveia-preta (Avena strigosa Schreber) é uma gramínea anual, rústica e pouco exigente que tem sido muito empregada para adubação verde e como planta de cobertura no SPD em rotação de culturas (DERPSCH \& CALEGARI, 1992; PÖTKER \& ROMAN, 1994), ocupando extensas áreas nos Estados da região Sul do Brasil, sudoeste de São Paulo e sul de Mato Grosso do Sul. Essa cultura tem como principais vantagens a boa capacidade de perfilhamento, a facilidade de aquisição de sementes e de implantação do cultivo, a resistência a pragas e doenças, o desenvolvimento inicial acelerado, com rapidez na formação da cobertura do solo, a elevada produção de fitomassa, mesmo em solos de baixa fertilidade, a tolerância à seca, em função do sistema radicular bastante desenvolvido e a baixa taxa de decomposição dos resíduos da parte aérea, quando comparado a leguminosas (DERPSCH \& CALEGARI, 1992; FLOSS, 2000; BORTOLINI et al., 2000). Assim, o seu cultivo como cultura de cobertura tem como benefícios a redução da erosão e do escoamento superficial, o aumento da infiltração de água e do conteúdo de carbono orgânico do solo, a intensificação da ciclagem de nutrientes, pela transferência de elementos das camadas mais profundas para a superfície, a redução da atividade do Al tóxico, o controle de plantas daninhas, além de outros (BAYER \& AMARAL, 2003; BORKERT et al., 2003; SANTI et al., 2003).

Entre os fatores que mais limitam a produtividade das culturas, estão os baixos valores de $\mathrm{pH}$ e os teores reduzidos de bases no solo, que pode prejudicar o crescimento radicular e a absorção de água e nutrientes, especialmente em região de inverno seco, onde os cultivos nessa época freqüentemente são afetados por deficiência hídrica. Assim, como a aplicação de corretivos em superfície pode reduzir a acidez e melhorar a disponibilidade de nutrientes no solo (RHEINHEIMER et al., 2000; CAIRES et al., 2003; 2004; 2005), pode também interferir na produção de fitomassa e no acúmulo de nutrientes pela aveia-preta. Contudo, RHEINHEIMER et al. (2000) não verificaram efeito da aplicação de calcário em superfície, em SPD já consolidado, na produção de matéria seca da aveiapreta. Porém, ainda há poucos trabalhos de pesquisa com a aveia-preta no que se refere à ciclagem de nutrientes em função da aplicação de calcário e gesso em superfície.

O presente trabalho objetivou avaliar a influência da aplicação de calcário e gesso em superfície, na implantação do SPD, sobre a produção de matéria seca, o teor e o acúmulo de nutrientes na parte aérea da aveia-preta, em região de inverno seco.

\section{MATERIAL E MÉTODOS}

O trabalho foi realizado na Fazenda Experimental Lageado da Faculdade de Ciências Agronômicas - UNESP, município de Botucatu, SP (48 $23^{\circ} \mathrm{W}$ e $22^{\circ} 51^{\prime} \mathrm{S}$, altitude de $765 \mathrm{~m}$ ). O clima da região é do tipo Cwa (Köppen), caracterizando-se como tropical de altitude, com inverno seco e verão quente e chuvoso. Os totais mensais de precipitação pluvial registrados na área experimental durante os meses de maio, junho e julho foram 52,9, 23,7 e 15,8mm, em 2003, e 133,5, 28,8 e 104,3mm, em 2004, respectivamente.

O solo do local é um Latossolo Vermelho distroférrico, o qual permaneceu dois anos em pousio. Em fevereiro de 2001, foi cultivada soja (safrinha) mediante preparo de solo convencional (uma aração e duas gradagens). Em outubro de 2001, a área experimental foi subsolada e semeou-se guandu (Cajanus cajan (L.) Millsp.), o qual foi manejado com triturador de palha em 02/10/2002. Em agosto de 2002, foram coletadas amostras na profundidade de $0-20 \mathrm{~cm}$, para caracterização química (RAIJ et al., 2001) e granulométrica (EMBRAPA, 1997) inicial do solo, cujos resultados foram: matéria orgânica 20,9g dm${ }^{-3} ; \mathrm{pH}(0,01$ mol L-1 de $\mathrm{CaCl}_{2}$ ), 4,2; P (resina), 9,2mg dm${ }^{-3}$; K, Ca, $\mathrm{Mg}$ e CTC, 1,2, 14,0, 5,0 e 58,0 $\mathrm{mmol}_{\mathrm{c}} \mathrm{dm}^{-3}$, respectivamente, saturação por bases, $37 \%$, e teores de areia, silte e argila, respectivamente de 545,108 e $347 \mathrm{~g} \mathrm{~kg}^{-1}$. O solo também apresentava $360 \mathrm{~g} \mathrm{~kg}$ de argila na camada de $20-40 \mathrm{~cm}$ de profundidade.

O delineamento experimental utilizado foi em blocos casualizados em esquema de parcelas subdivididas, com quatro repetições. As parcelas (18,0 x 5,4m) foram constituídas por quatro doses de calcário dolomítico $\left(0,1.100,2.700\right.$ e $\left.4.300 \mathrm{~kg} \mathrm{ha}^{-1}\right)$, que apresentava 23,3\% de $\mathrm{CaO}, 17,5 \%$ de $\mathrm{MgO}$ e $71 \%$ de PRNT, visando a elevar a saturação por bases para $50 \%, 70 \%$ e $90 \%$, respectivamente. As subparcelas (5,4 x 9,0m) foram constituídas pela ausência ou presença da aplicação de $2.100 \mathrm{~kg} \mathrm{ha}^{-1}$ de gesso agrícola (20\% de Ca e $16 \%$ de $S$ ), sendo a dose igual a seis vezes o teor 
de argila em $\mathrm{g} \mathrm{kg}^{-1}$, na camada de 0,20-0,40m de profundidade. Foram mantidas distâncias de 8,0m entre as parcelas dentro de cada bloco e de 3,0m entre os blocos. Para as avaliações foram descartadas as bordaduras de $0,5 \mathrm{~m}$ nas extremidades de cada unidade experimental.

A calagem foi realizada no dia 15/10/2002, nas parcelas onde estava previsto este tratamento. No dia 16/10/2002, realizou-se a aplicação de gesso agrícola em metade de todas as parcelas. O calcário e o gesso foram aplicados superficialmente, sem incorporação ao solo.

Nas safras de verão dos anos agrícolas de 2002/03 e 2003/04, foram cultivadas, em toda a área experimental, as culturas de arroz e feijão, respectivamente. A adubação básica, em ambos os cultivos, foi de $300 \mathrm{~kg} \mathrm{ha}^{-1}$ da fórmula-NPK 08-28-16 + 4,5\% de S + 0,5\% de Zn, em 20/11/2002 e 06/01/2004.

Após as colheitas das culturas de verão foi semeada aveia-preta, cv “Comum”, em 30/04/2003 e 26/ 04/2004, em toda a área experimental, num espaçamento entre linhas de $0,17 \mathrm{~m}$ e cerca de 70 sementes por metro. Cada subparcela foi constituída por 26 linhas de 9 metros de comprimento. A adubação básica aplicada por ocasião da semeadura, foi de $200 \mathrm{~kg} \mathrm{ha}^{-1}$ da fórmulaNPK 10-20-10 + 4,5\% de S no primeiro ano, e 200 $\mathrm{kg} \mathrm{ha}^{-1}$ de 04-20-10 + 7,0\% de S no segundo ano. A emergência das plantas ocorreu em 08/05/2003 e 02/05/2004.

Antes das semeaduras da aveia-preta, ou seja, aos $6(15 / 04 / 2003)$ e 18 (19/04/2004) meses após a aplicação dos corretivos, foram realizadas amostragens de solo, nas camadas de $0-5,5-10$ e $10-20 \mathrm{~cm}$ de profundidade, para análise química, coletando-se sete subamostras na área útil de cada subparcela, para constituir uma amostra composta, sempre na entrelinha da cultura, com a utilização de trado calador. As amostras foram submetidas à análise para determinação do $\mathrm{pH}\left(0,01 \mathrm{~mol} \mathrm{~L}^{-1} \mathrm{CaCl}_{2}\right), \mathrm{Ca}^{2+}, \mathrm{Mg}^{2+}$ e calculadas as relações $\mathrm{K} /(\mathrm{Ca}+\mathrm{Mg}), \mathrm{Ca} / \mathrm{Mg}$ e a saturação por bases, conforme RAIJ et al. (2001). O S-SO ${ }_{4}{ }^{2-}$ foi determinado segundo VITTI (1988). Os resultados estão apresentados na tabela 1.

Em 19/07/2003 e 16/07/2004, por ocasião do florescimento da cultura, realizou-se a coleta da parte aérea das plantas contidas em $2 \mathrm{~m}$ de fileira, em cada subparcela. O material coletado foi acondicionado em sacos de papel e levado para secagem em estufa a $65^{\circ} \mathrm{C}$ até peso constante. Em seguida, as amostras foram pesadas para a determinação da matéria seca e moídas em moinho tipo Willey. A avaliação dos teores de macro (N, P, K, Ca, Mg e S) e micronutrientes (Cu, Fe, Mn e $\mathrm{Zn}$ ) foi realizada segundo método descrito por MALAVOLTA et al (1997). De posse desses resultados, foram estimadas as quantidades acumuladas desses nutrientes por área, de acordo com os tratamentos.

Os dados foram submetidos à análise de variância. As médias referentes à aplicação de gesso foram comparadas pelo teste t a $5 \%$ de probabilidade. Os efeitos das doses de calcário foram avaliados por meio de análise de regressão, adotando-se como critério para escolha do modelo a magnitude dos coeficientes de regressão significativos ao nível de 5\% de probabilidade pelo teste $\mathrm{t}$.

\section{RESULTADOS E DISCUSSÃO}

A aplicação de calcário em superfície, apesar de ter melhorado as características químicas do solo, principalmente, nas camadas superficiais (Tabela 1), não afetou a produção de matéria seca na parte aérea da cultura da aveia-preta, em nenhum dos anos de cultivos (Tabela 2). A ausência de resposta da produção de matéria seca pela cultura da aveia-preta à aplicação superficial de calcário se deve aos médios a altos valores de Ca e Mg no solo (Tabela 1). Assim, essas condições podem não ter restringido o crescimento da aveia-preta, mesmo no tratamento sem a aplicação de calcário, semelhante aos resultados obtidos por RHEINHEIMER et al. (2000). Por outro lado, a aplicação de gesso proporcionou maior produção de matéria seca no primeiro ano de cultivo, com acréscimo de 705kg ha-1 , o que representa um aumento de 15,6\% em relação ao tratamento sem aplicação (Tabela 2). Os resultados podem estar relacionados com o aumento dos teores de Ca no perfil do solo e de S-SO ${ }_{4}{ }^{2-}$, de maneira especial, nas camadas mais profundas (Tabela 1 ), o que pode ter favorecido o crescimento radicular em profundidade, diminuindo os efeitos da deficiência hídrica ocorrida durante o desenvolvimento da cultura, em 2003. De acordo com CAIRES et al. (1999) e CAIRES et al. (2001), a melhoria do teor de sulfato no perfil do solo é de extrema importância para manter a produtividade de culturas gramíneas, principalmente, em condições de déficit hídrico.

A ausência de efeitos dos tratamentos e a maior produção de matéria seca, no segundo ano de cultivo, podem estar relacionadas com a maior disponibilidade hídrica, já que da emergência ao florescimento da aveia-preta foram registrados $218 \mathrm{~mm}$ de chuvas na área do experimento, precipitação bastante superior a do primeiro ano (57mm). Além disso, no segundo ano de cultivo, a aveia foi semeada em sucessão à cultura do feijão, o que pode ter promovido maior disponibilidade de nutrientes à cultura, especialmente $\mathrm{N}$, favorecendo o desenvolvimento da mesma. Como os resíduos da cultura do feijão (parte 
Tabela 1 - Resultado da análise química de amostras de solo coletadas nas camadas de 0-5, 5-10 e 10-20 cm de profundidade, aos 6 e 18 meses após a aplicação de calcário e gesso agrícola em superfície de Latossolo Vermelho distroférrico. Médias de quatro repetições.

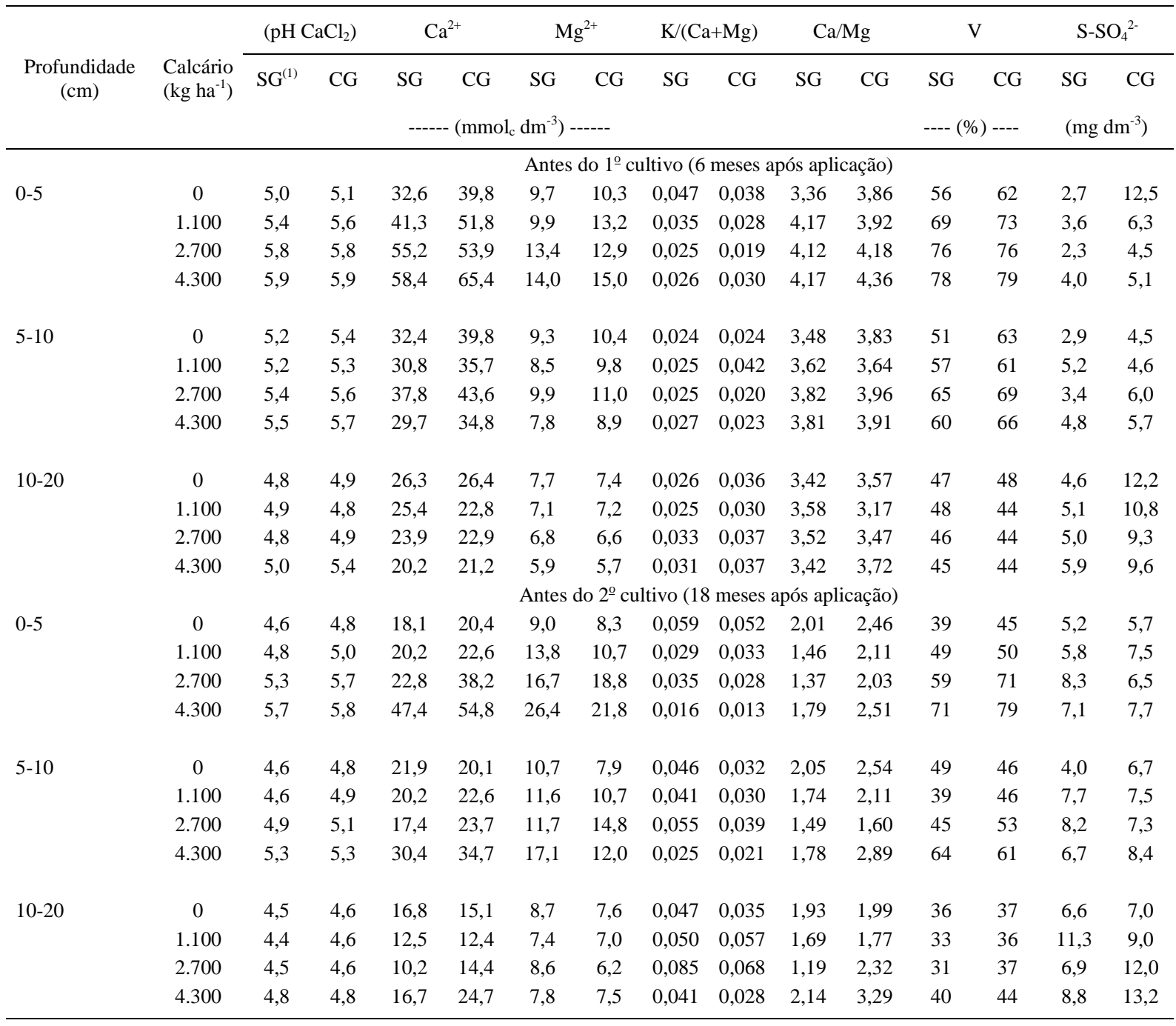

(1) SG indica os tratamentos sem aplicação de gesso e CG os tratamentos com aplicação de gesso (2.100 kg ha-1).

aérea e raízes) têm uma baixa relação $\mathrm{C} / \mathrm{N}$, podem ter disponibilizado rapidamente os nutrientes para a cultura da aveia-preta. No entanto, nos dois anos de cultivo, a aveia-preta apresentou elevada produção de matéria seca (Tabela 2), com valores próximos aos encontrados por CALEGARI (1990) no sul do Paraná (4,7 a 7,3t ha-1), e dos relatados por BORKERT et al. (2003).

Os teores de N na parte área da aveia-preta não foram influenciados pela aplicação de calcário em superfície (Tabela 2). No entanto, no primeiro ano de cultivo, a aplicação de gesso aumentou a concentração de $\mathrm{N}$, o que se deve, provavelmente, aos efeitos benéficos desse produto em melhorar as condições químicas do subsolo, estimulando a absorção de $\mathrm{N}$ do maior volume de solo explorado, principalmente, em condições de deficiência hídrica, como as observadas no ano de 2003, no qual os valores de precipitação foram baixos. Esses resultados corroboram os observados para outras culturas, como: sorgo (RAIJ et al., 1988), milho (SOUSA \& RITCHEY, 1986; CAIRES et al., 2004) e cevada (CAIRES et al., 2001), em que também não foram obtidos efeitos da calagem no teor de $\mathrm{N}$ na planta.

Quanto aos teores de P, houve efeito da interação calagem e gesso em superfície no segundo ano de cultivo (Tabela 2). O tratamento sem aplicação de corretivos promoveu maior teor de $\mathrm{P}$ na parte aérea da aveia-preta (Tabela 3). Nos dois anos de cultivo, os 
Tabela 2 - Produção de matéria seca (MS) e teores de N, P, K, Ca, Mg, S, Cu, Fe, Mn e Zn, na parte aérea da aveia-preta em função da aplicação de calcário e gesso agrícola em superfície, na implantação do sistema plantio direto. Botucatu (SP).

\begin{tabular}{|c|c|c|c|c|c|c|c|c|c|c|c|}
\hline \multirow{2}{*}{ Tratamentos } & \multirow{2}{*}{$\begin{array}{c}\text { MS } \\
\left(\mathrm{kg} \mathrm{ha}^{-1}\right)\end{array}$} & $\mathrm{N}$ & $\mathrm{P}$ & K & $\mathrm{Ca}$ & $\mathrm{Mg}$ & S & $\mathrm{Cu}$ & $\mathrm{Fe}$ & Mn & $\mathrm{Zn}$ \\
\hline & & \multicolumn{6}{|c|}{ - } & \multicolumn{4}{|c|}{ 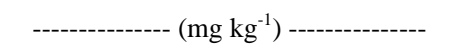 } \\
\hline Calcário $\left(\mathrm{kg} \mathrm{ha}^{-1}\right)$ & & & & & & 2003 & & & & & \\
\hline 0 & 4.964 & 19,6 & 1,7 & 13,8 & 3,6 & 2,9 & 1,4 & 9,7 & 320,9 & 215,1 & 22,0 \\
\hline 1.100 & 4.994 & 20,0 & 1,6 & 14,0 & 3,4 & 3,0 & 1,5 & 7,5 & 247,7 & 242,4 & 19,2 \\
\hline 2.700 & 4.543 & 19,2 & 1,7 & 13,1 & 3,5 & 3,2 & 1,2 & 8,2 & 124,2 & 179,3 & 27,3 \\
\hline 4.300 & 5.015 & 19,2 & 1,7 & 13,5 & 3,3 & 3,1 & 1,2 & 10,1 & 164,6 & 213,7 & 24,5 \\
\hline Regressão & ns & ns & ns & - & - & ns & ns & ns & $\mathrm{Q}^{(1)}$ & ns & ns \\
\hline CV (\%) & 11,8 & 17,7 & 23,1 & 11,3 & 18,6 & 16,7 & 38,0 & 51,2 & 65,6 & 29,9 & 56,6 \\
\hline \multicolumn{12}{|l|}{ Gesso } \\
\hline Sem & $4.526 \mathrm{~b}$ & $18,7 \mathrm{~b}$ & $1,7 \mathrm{a}$ & 14,3 & 3,3 & 3,3 a & $1,0 \mathrm{~b}$ & 8,2 a & 189,6 а & 203,7 a & $19,6 \mathrm{a}$ \\
\hline Com & $5.231 \mathrm{a}$ & 20,3 a & $1,7 \mathrm{a}$ & 12,9 & 3,6 & $2,8 \mathrm{~b}$ & $1,7 \mathrm{a}$ & 8,5 a & 239,1 a & 221,4 a & $27,2 \mathrm{a}$ \\
\hline CV (\%) & 15,7 & 7,0 & 13,1 & 11,8 & 14,7 & 14,1 & 27,1 & 37,8 & 49,2 & 8,8 & 48,3 \\
\hline Interação CxG & ns & ns & ns & $*$ & $*$ & ns & ns & ns & ns & ns & ns \\
\hline Calcário $\left(\mathrm{kg} \mathrm{ha}^{-1}\right)$ & & & & & & 2004 & & & & & \\
\hline 0 & 6.316 & 21,2 & 1,9 & 14,8 & 5,1 & 1,4 & 2,8 & 19,3 & 175,3 & 296,7 & 38,1 \\
\hline 1.100 & 6.380 & 21,5 & 1,6 & 16,4 & 5,4 & 1,4 & 3,8 & 17,3 & 194,5 & 330,0 & 36,8 \\
\hline 2.700 & 6.322 & 22,8 & 1,9 & 17,6 & 5,9 & 1,8 & 3,3 & 15,5 & 222,0 & 242,0 & 35,9 \\
\hline 4.300 & 6.009 & 20,8 & 1,8 & 16,5 & 5,7 & 1,4 & 3,2 & 17,3 & 231,5 & 243,0 & 36,4 \\
\hline Regressão & $\mathrm{ns}$ & ns & - & ns & - & ns & $\mathrm{Q}^{(2)}$ & ns & ns & $\mathrm{L}^{(3)}$ & ns \\
\hline CV (\%) & 9,3 & 13,6 & 18,1 & 29,8 & 14,5 & 25,9 & 15,7 & 61,3 & 58,4 & 20,2 & 40,2 \\
\hline \multicolumn{12}{|l|}{ Gesso } \\
\hline Sem & 6.240 а & $21,7 \mathrm{a}$ & 1,9 & $15,6 \mathrm{a}$ & 5,6 & $1,6 \mathrm{a}$ & $2,8 \mathrm{~b}$ & $16,1 \mathrm{a}$ & 193,1 а & 294,8 а & $35,8 \mathrm{a}$ \\
\hline Com & $6.274 \mathrm{a}$ & $21,4 \mathrm{a}$ & 1,7 & $17,1 \mathrm{a}$ & 5,4 & $1,5 \mathrm{a}$ & 3,8 a & $18,5 \mathrm{a}$ & 218,6 a & $261,1 \mathrm{~b}$ & 37,9 a \\
\hline CV (\%) & 14,7 & 8,6 & 10,8 & 17,2 & 12,6 & 11,1 & 19,1 & 42,3 & 64,6 & 10,9 & 33,8 \\
\hline Interação CxG & ns & ns & * & ns & * & ns & ns & ns & ns & ns & ns \\
\hline
\end{tabular}

Médias seguidas de letras distintas, na coluna, para o fator gesso, diferem entre si pelo teste $\mathrm{t}(\mathrm{P}=0,05)$. Interação: ns=não significativo e *=Significativo, pelo teste $\mathrm{t}(\mathrm{P}<0,05) .{ }^{(1)} \mathrm{y}=331,74-0,12 \mathrm{x}+0,00002 \mathrm{x}^{2} \mathrm{R}^{2}=0,95^{*} ;{ }^{(2)} \mathrm{y}=2,99+0,00051 \mathrm{x}-0,0000001 \mathrm{x}^{2} \mathrm{R}^{2}=0,47 * ;{ }^{(3)} \mathrm{y}=314,28-$ $0,018 x \mathrm{R}^{2}=0,61^{*}$.

teores de $\mathrm{P}$ em todos os tratamentos foram maiores que os verificados por BORKERT et al. (2003).

Os teores de $\mathrm{K}$ e Ca foram influenciados apenas pela interação entre os fatores no primeiro ano de cultivo e o de Ca, no segundo ano (Tabela 2). Por meio da tabela 3 , verifica-se que a aplicação de gesso na ausência de calagem reduziu o teor de K na parte aérea da cultura, o que pode ter sido conseqüência da maior absorção de Ca devido à redução na relação K/ (Ca+Mg) em razão da maior disponibilidade Ca no solo decorrente da aplicação de gesso (Tabela 1). Deve ser ressaltado que não houve redução do teor de $\mathrm{K}$ do solo, e sim aumento da quantidade de Ca, refletindo na menor absorção de K, uma vez que esses cátions competem pelo mesmo sítio de absorção na planta. BÜLL et al. (1993) verificaram que a redução nos valores da relação $\mathrm{K} /(\mathrm{Ca}+\mathrm{Mg})$, tanto em solos de textura média, quanto nos argilosos, proporcionaram deficiência de potássio em Panicum maximum L. cv. “Tobiatã”. RAIJ et al. (1998) também verificaram redução nos teores de $\mathrm{K}$ e aumento nos teores de Ca em folhas de milho em função da aplicação de gesso. No segundo ano de cultivo, a aplicação de calcário em superfície, quando na ausência de gesso, promoveu acréscimo linear nos teores de Ca na parte área da aveia-preta (Tabela 3), que reflete o aumento nos teores desse elemento no solo, principalmente nas camadas superficiais (Tabela $1)$.

A calagem não afetou o teor de Mg no tecido vegetal, em nenhum dos anos de cultivo (Tabela 2). A aplicação de gesso em superfície proporcionou menor teor de Mg na parte aérea da aveia-preta, no primeiro ano de cultivo, podendo estar relacionada ao aumento 
Produção de fitomassa e acúmulo de nutrientes pela aveia-preta em função da aplicação de calcário e gesso...

Tabela 3 - Desdobramento da interação calcário x gesso agrícola para os teores de K e Ca (2003) e, de P e Ca (2004), na parte aérea da aveiapreta.

\begin{tabular}{|c|c|c|c|c|c|}
\hline \multirow{2}{*}{ Gesso } & \multicolumn{4}{|c|}{ - } & \multirow[b]{2}{*}{ Regressão } \\
\hline & 0 & 1.100 & 2.700 & 4.300 & \\
\hline \multicolumn{6}{|c|}{2003} \\
\hline Sem & 15,2 a & 14,0 a & 13,3 a & 14,8 a & ns \\
\hline Com & $12,5 \mathrm{~b}$ & $14,0 \mathrm{a}$ & 12,9 a & $12,1 \mathrm{~b}$ & ns \\
\hline Sem & $3.1 \mathrm{~b}$ & 3,5 a & 3.3 а & $3.4 \mathrm{a}$ & ns \\
\hline Com & $4,1 \mathrm{a}$ & 3,4 a & 3,6 a & 3,2 a & ns \\
\hline \multicolumn{6}{|c|}{2004} \\
\hline Sem & 2,3 a & $1,6 \mathrm{a}$ & 1,9 a & 1,8 a & ns \\
\hline Com & $1,6 \mathrm{~b}$ & 1,7 a & 1,8 a & 1,8 a & ns \\
\hline Sem & $4.9 \mathrm{a}$ & 5.7 a & $5.8 \mathrm{a}$ & $6.1 \mathrm{a}$ & $\mathrm{L}^{(1)}$ \\
\hline Com & 5,3 a & $5,1 \mathrm{a}$ & 6,0 a & 5,2 a & ns \\
\hline
\end{tabular}

Médias seguidas de letras distintas na coluna, para cada variável, diferem entre si pelo teste t $(\mathrm{P}=0,05)$.

${ }^{(1)} \mathrm{y}=5,09+0,00025 \times \mathrm{R}^{2}=0,82 *$.

da relação Ca/Mg no solo, proporcionada pela aplicação de gesso (Tabela 1). De acordo com CAIRES et al. (2001), o gesso aumenta o teor de Ca no solo e proporciona movimentação do Mg para camadas mais profundas. Contudo, no presente trabalho não foi constatado movimentação de Mg no perfil do solo com aplicação de gesso, mediante a amostragem de solo até a profundidade de $20 \mathrm{~cm}$, mas sim elevação dos valores da relação $\mathrm{Ca} / \mathrm{Mg}$.

A calagem aumentou a absorção de S no segundo ano de cultivo, com os dados sendo ajustados a uma função quadrática (Tabela 2). A maior absorção de S com a aplicação de calcário pode ser conseqüência da liberação de sulfato adsorvido, em decorrência da elevação do $\mathrm{pH}$ na camada superficial do solo (CAIRES et al., 1999), ou ainda, da maior mineralização de $S$ orgânico, considerando o ambiente mais favorável para a atividade microbiana (WILLIAMS, 1967). A aplicação de gesso promoveu aumento no teor $\mathrm{S}$ nos dois anos de cultivo. Deve-se ressaltar que o gesso é excelente fonte desse nutriente. Assim, o aumento nos teores de $\mathrm{S}-\mathrm{SO}_{4}{ }^{2-}$ no solo, proporcionado pela aplicação de gesso, especialmente nas camadas mais profundas (Tabela 1), possibilitou maior absorção de S pelas plantas, corroborando os resultados obtidos por CAIRES et al. (2001) e CAIRES et al. (2002) em cevada e trigo, respectivamente.

A calagem reduziu os teores de $\mathrm{Fe}$, no primeiro ano de cultivo, e de $\mathrm{Mn}$, no segundo ano (Tabela 2), em razão da diminuição da disponibilidade desses nutrientes pela elevação do $\mathrm{pH}$ do solo (HARMSEN \& VLEK, 1985). A aplicação de gesso influenciou apenas a absorção de Mn, em 2004, reduzindo o teor desse elemento na parte aérea da aveia-preta.
Para as quantidades acumuladas de nutrientes na parte aérea da aveia-preta, não houve efeito significativo da interação calcário e gesso (Tabela 4). Quanto ao efeito da calagem em superfície, os resultados refletiram o observado para os teores (Tabela 2), ou seja, a aplicação de calcário aumentou a quantidade acumulada de S na parte aérea da aveiapreta, em 2004, e reduziu o acúmulo de Fe, em 2003, e de Mn, em 2004.

Como verificado para a produção de matéria seca e para o teor de N, Ca e S, a aplicação de gesso em superfície incrementou a quantidade desses nutrientes acumulada por área, no primeiro cultivo, além de aumentar também o acúmulo de Fe e Zn (Tabela 4). Em 2004, a aplicação de gesso aumentou o acúmulo de S na parte aérea da aveia-preta, conseqüência do aumento no teor desse elemento no solo e na planta (Tabela $1 \mathrm{e}$ 2). De acordo com BORKERT et al. (2003), a aveiapreta é uma eficiente recicladora de nutrientes por possuir sistema radicular profundo, característica que pode ter sido favorecida, no primeiro ano de cultivo, pela aplicação de gesso. O gesso, devido a sua maior solubilidade, é considerado mais eficiente que o calcário para aumentar o suprimento de Ca e reduzir a toxidez de alumínio no solo (SUMNER, 1995), favorecendo o desenvolvimento das raízes em profundidade, abaixo da camada corrigida pela calagem.

\section{CONCLUSÕES}

A aplicação de calcário em superfície não afeta a produção de matéria seca da aveia-preta em SPD, tanto na presença quanto na ausência de gesso. A aplicação de gesso agrícola em superfície eleva os teores de $\mathrm{Ca}$ e $\mathrm{S}-\mathrm{SO}_{4}{ }^{2-}$ no solo e a absorção de S pela 
Tabela 4 - Quantidades de N, P, K, Ca, Mg, S, Cu, Fe, Mn e Zn acumuladas na parte aérea da aveia-preta em função da aplicação de calcário e gesso agrícola em superfície, na implantação do sistema plantio direto. Botucatu (SP).

\begin{tabular}{|c|c|c|c|c|c|c|c|c|c|c|}
\hline \multirow{2}{*}{ Tratamentos } & $\mathrm{N}$ & $\mathrm{P}$ & $\mathrm{K}$ & $\mathrm{Ca}$ & \multicolumn{2}{|c|}{$\mathrm{S}$} & $\mathrm{Cu}$ & $\mathrm{Fe}$ & Mn & $\mathrm{Zn}$ \\
\hline & \multicolumn{6}{|c|}{----------------------------- $\left(\mathrm{kg} \mathrm{ha}^{-1}\right)$---------------------------- } & \multicolumn{4}{|c|}{----------------- $\left(\mathrm{g} \mathrm{ha}^{-1}\right.$ ) ----------------- } \\
\hline Calcário (kg ha-1) & \multicolumn{10}{|c|}{2003} \\
\hline 0 & 98,2 & 8,4 & 68,2 & 18,1 & 14,1 & 7,3 & 48,8 & $1.765,4$ & $1.065,0$ & 108,2 \\
\hline 1.100 & 99,2 & 8,0 & 69,2 & 17,1 & 15,1 & 7,1 & 34,7 & $1.270,9$ & $1.226,6$ & 93,7 \\
\hline 2.700 & 87,7 & 7,7 & 59,4 & 15,7 & 14,4 & 5,6 & 36,9 & 569,8 & 817,5 & 128,0 \\
\hline 4.300 & 96,1 & 8,7 & 66,7 & 16,6 & 15,6 & 6,3 & 50,7 & 865,6 & $1.077,1$ & 125,9 \\
\hline Regressão & ns & ns & ns & ns & ns & ns & ns & $\mathrm{Q}^{(1)}$ & ns & ns \\
\hline CV (\%) & 23,0 & 22,8 & 19,0 & 20,2 & 16,7 & 38,2 & 56,3 & 57,4 & 32,9 & 54,2 \\
\hline \multicolumn{11}{|l|}{ Gesso } \\
\hline Sem & $85,5 b$ & $7,7 a$ & $64,4 a$ & $15,0 b$ & $14,6 a$ & $4,4 b$ & $37,5 a$ & $907,4 b$ & $1.018,5 a$ & $87,4 \mathrm{~b}$ \\
\hline Com & $105,2 a$ & $8,7 a$ & $67,3 a$ & $18,8 \mathrm{a}$ & $15,0 \mathrm{a}$ & 8,8a & $44,5 a$ & $1.328,4 \mathrm{a}$ & $1.075,1 \mathrm{a}$ & $140,5 a$ \\
\hline CV (\%) & 17,6 & 21,9 & 17,0 & 26,1 & 21,5 & 35,4 & 49,7 & 51,2 & 20,5 & 49,5 \\
\hline Interação CxG & ns & ns & ns & ns & ns & ns & ns & ns & ns & ns \\
\hline Calcário (kg ha-1) & \multicolumn{10}{|c|}{2004} \\
\hline 0 & 133,5 & 11,9 & 93,3 & 32,5 & 9,0 & 18,0 & 121,3 & $1.107,5$ & $1.865,4$ & 239,6 \\
\hline 1.100 & 136,3 & 10,5 & 103,0 & 34,6 & 9,1 & 23,5 & 110,4 & $1.243,4$ & $2.094,3$ & 227,7 \\
\hline 2.700 & 143,5 & 11,7 & 109,6 & 37,0 & 11,2 & 20,7 & 98,6 & $1.380,2$ & $1.530,9$ & 223,7 \\
\hline 4.300 & 125,2 & 10,8 & 100,1 & 34,0 & 8,7 & 18,9 & 111,0 & $1.375,5$ & $1.438,0$ & 219,6 \\
\hline Regressão & ns & ns & ns & ns & ns & $\mathrm{Q}^{(2)}$ & ns & ns & $\mathrm{L}^{(3)}$ & ns \\
\hline CV (\%) & 15,0 & 20,2 & 29,6 & 22,1 & 32,7 & 13,3 & 45,4 & 46,1 & 16,3 & 35,8 \\
\hline \multicolumn{11}{|l|}{ Gesso } \\
\hline Sem & $135,2 \mathrm{a}$ & $10,8 \mathrm{a}$ & $98,1 \mathrm{a}$ & $35,0 \mathrm{a}$ & $9,7 \mathrm{a}$ & $17,2 b$ & $104,3 a$ & $1.199,2 \mathrm{a}$ & $1.843,0 \mathrm{a}$ & 223,9 \\
\hline Com & $134,0 \mathrm{a}$ & $11,6 a$ & $105,2 a$ & $34,0 \mathrm{a}$ & $9,2 \mathrm{a}$ & $23,4 a$ & $116,4 a$ & $1.354,2 \mathrm{a}$ & $1.621,3 \mathrm{a}$ & 231,4 \\
\hline CV (\%) & 17,8 & 16,4 & 22,8 & 20,0 & 17,8 & 21,9 & 33,5 & 44,6 & 16,7 & 33,5 \\
\hline Interação CxG & ns & ns & ns & ns & ns & ns & ns & ns & ns & ns \\
\hline
\end{tabular}

Médias seguidas de letras distintas, na coluna, para o fator gesso, diferem entre si pelo teste $\mathrm{t}(\mathrm{P}=0,05)$. Interação: ns=não significativo, pelo teste $\mathrm{t}(\mathrm{P}<0,05)$. ${ }^{(1)} \mathrm{y}=1.822,61-0,75 \mathrm{x}+0,00012 \mathrm{x}^{2} \mathrm{R}^{2}=0,96^{*} ;{ }^{(2)} \mathrm{y}=18,80+0,0035 \mathrm{x}-0,000001 \mathrm{x}^{2} \quad \mathrm{R}^{2}=0,63^{* *} ;{ }^{(3)} \mathrm{y}=2001,84-0,133 \mathrm{x} \quad \mathrm{R}^{2}=0,68 * *$.

cultura da aveia-preta, assim como favorece a produção de matéria seca, aumenta os teores de $\mathrm{N}$ e Ca e o acúmulo de N, Ca, Fe e Zn pela aveia-preta em SPD, em ano com menor disponibilidade hídrica.

\section{AGRADECIMENTOS}

À Fundação de Amparo à Pesquisa do Estado de São Paulo (FAPESP) e ao Conselho Nacional de Desenvolvimento Científico e Tecnológico (CNPq), pela concessão de bolsas ao primeiro e segundo autores, respectivamente.

\section{REFERÊNCIAS}

BAYER, C.; AMARAL, A.S. Amenização da acidez de um latossolo argiloso por extratos aquosos de plantas de cobertura de inverno. Revista de Ciências Agroveterinárias, v.2, p.88-96, 2003.

BORKERT, C.M. et al. Nutrientes minerais na biomassa da parte aérea em culturas de cobertura do solo. Pesquisa Agropecuária Brasileira, v.38, p.143-153, 2003.

BORTOLINI, C.G. et al. Efeito de resíduos de plantas jovens de aveia preta em cobertura de solo no crescimento inicial do milho. Pesquisa Agropecuária Gaúcha, v.6, p.83-88, 2000.

BÜLL, L.T. et al. Influência da relação $\mathrm{K} /(\mathrm{Ca}+\mathrm{Mg})$ do solo na produção de matéria seca e na absorção de potássio por gramínea e leguminosa forrageiras. II. Absorção de potássio em função da relação $\mathrm{K} /(\mathrm{Ca}+\mathrm{Mg})$ no complexo de troca do solo. Científica, v.21, p.67-75, 1993.

Ciência Rural, v.38, n.4, jul, 2008. 
CAIRES, E.F. et al. Surface application of lime for crop grain production under a no-till system. Agronomy Journal, v.97, p.791-798, 2005.

CAIRES, E.F. et al. Alterações químicas do solo e resposta da soja ao calcário e gesso aplicados na implantação do sistema de plantio direto. Revista Brasileira de Ciência do Solo, v.27, p.275-286, 2003

CAIRES, E.F. et al. Produção de milho, trigo e soja em função das alterações das características químicas do solo pela aplicação de calcário e gesso na superfície, em sistema de plantio direto. Revista Brasileira de Ciência do Solo, v.23, p.315-327, 1999.

CAIRES, E.F. et al. Crescimento radicular e nutrição da cevada em função da calagem e aplicação de gesso. Bragantia, v.60 p.213-223, 2001

CAIRES, E.F. et al. Alterações químicas do solo e resposta do milho à calagem e aplicação de gesso. Revista Brasileira de Ciência do Solo, v.28, p.125-136, 2004.

CALEGARI, A. Plantas para adubação verde de inverno no sudoeste do Paraná. Londrina: Instituto Agronômico do Paraná, 1990. 37p. (Boletim Técnico, 35).

DERPSCH, R.; CALEGARI, A. Plantas para adubação verde de inverno. Londrina: IAPAR, 1992. 80p. (Circular, 73).

EMPRESA BRASILEIRA DE PESQUISA AGROPECUÁRIA EMBRAPA. Centro Nacional de Pesquisa de Solos. Manual de métodos de análise de solo. 2.ed. Brasília: EmbrapaCNPS, 1997. 212p. (Documentos, 1).

FEDERAÇÃO BRASILEIRA DE PLANTIO DIRETO NA PALHA - FEBRAPDP. Evolução do plantio direto no Brasil. Acesso em: 05 abr. 2006. On line. Disponível em: <http:// www.febrapdp.org.br>.

FLOSS, E.L. Benefícios da biomassa de aveia preta ao sistema plantio direto. Revista Plantio Direto, p.25-29, 2000.

HARMSEN, K.; VLEK, P.L.G. The chemistry of micronutrients in soil. Fertilizer Research, v.7, p.1-42, 1985

MALAVOLTA, E. et al. Avaliação do estado nutricional de plantas: princípios e aplicações. 2.ed. Piracicaba: Potafos, 1997. 319p.
PÖTKER, D.; ROMAN, E.S. Efeito de resíduos de culturas e do pousio de inverno sobre a resposta do milho a nitrogênio. Pesquisa Agropecuária Brasileira, v.29, p.763-770, 1994.

RAIJ, B. et al. Análise química para avaliação da fertilidade de solos tropicais. Campinas: Instituto Agronômico, 2001. 284p.

RAIJ, B. et al. Efeito, na reação do solo, da absorção de amônio e nitrato pelo sorgo, na presença e na ausência de gesso. Revista Brasileira de Ciência do Solo, v.12, p.131-136, 1988.

RAIJ, B. et al. Gesso na produção de cultivares de milho com tolerância diferencial a alumínio em três níveis de calagem. Revista Brasileira de Ciência do Solo, v.22, p.101-108, 1998.

RHEINHEIMER, D.S. et al. Aplicação superficial de calcário no sistema plantio direto consolidado em solo arenoso. Ciência Rural, v.30, p.263-268, 2000.

SANTI, A. et al. Adubação nitrogenada na aveia preta. I Influência na produção de matéria seca e ciclagem de nutrientes sob sistema plantio direto. Revista Brasileira de Ciência do Solo, v.27, p.1075-1083, 2003

SOUSA, D.M.G.; RITCHEY, K.D. Uso de gesso no solo de cerrado. In: SEMINÁRIO SOBRE O USO DE FOSFOGESSO NA AGRICUlTURA, 1986, Brasília, DF. Anais... Brasília: EMBRAPA-DDT, 1986. p.119-144

SUMNER, M.E. Amelioration of subsoil acidity with minimum disturbance. In: JAYAWARDANE, N.S.; STEWART, B.A. (Ed.). Subsoil management techniques. Athens: Lewis Publishers, 1995. p.147-185.

VITTI, G.C. Enxofre no solo. In: SIMPOSIO SOBRE INTERPRETAÇÃO DE ANÁLISE QUÍMICA DE SOLO E PLANTA PARA FINS DE ADUBAÇÃO, 1988, Botucatu, SP. Anais... Botucatu: FCA-UNESP/FEPAF/ANDA/POTAFOS, 1988. 39p.

WILLIAMS, C.H. Some factors affecting the mineralization of organic sulfur in soils. Plant Soil, v.26, p.205-223, 1967. 